\title{
The Chinese Mode of Supporting Social Organizations: A New Framework
}

\author{
Hao Shi ${ }^{1,2}$ \\ ${ }^{1}$ School of Public Affairs, Zhejiang University, Hangzhou, China \\ ${ }^{2}$ Center of Social Welfare and Governance, Zhejiang University, Hangzhou, China
}

Email address:

shihaojenny@foxmail.com

\section{To cite this article:}

Hao Shi. The Chinese Mode of Supporting Social Organizations: A New Framework. Humanities and Social Sciences. Vol. 7, No. 2, 2019, pp. 58-66. doi: 10.11648/j.hss.20190702.12

Received: May 11, 2019; Accepted: May 31, 2019; Published: June 13, 2019

\begin{abstract}
As an important part of the ecological chains of social organizations, the supporting social organizations is committed to provide all-round support for service-oriented social organizations including capabilities, funding, and strategic guidance. Under the historical and political influence, the Chinese supporting social organizations are not only effective in helping and supportive, but also in accepting the transfer of government functions and meeting the needs of social governance. In view of the complexity and diversity of the current development environment, the initiator and sources of funds as two dimensions basically determine the genes and the future development direction of one supporting social organization. On this basis, four development modes, including the acting government mode, the governmental and social binding mode, the social multivariate mode and the consortium dominant mode, are summarized in this paper and each mode is illustrated respectively by one case selected. In addition, an analytical framework for the supporting social organizations with Chinese characteristics is constructed, and the relevant policy recommendations are also put forward in this paper.
\end{abstract}

Keywords: Supporting Social Organizations, Classification Framework, Initiator, Sources of Funds

\section{Introduction}

It is not excessive to describe a supporting social organization in a way that its helping, financing and promoting for ordinary social organizations is as critical as angel investors for startups. After 16 years of development, the Global Alliance for Improved Nutrition (GAIN) has now grown into one organization that is able to provide nutritious food for more than 700 million poor people each year. The secret behind its success comes from several supporting social organizations, including the world-renowned Bill \& Melinda Gates Foundation. As for its value, the supporting social organizations are not only effective in their initial development, but also in their long-term guidance and assistance for other social organizations.

As a new form of organizations, the supporting social organizations have also attracted the attention of the academic community. In 1987, Stremlau first proposed the concept prototype, "coordination group", which believed that it served social organizations and established a bridge of communication between the government and social organizations, with supportive grassroots as its one remarkable feature $[1,2]$. As the practice of supporting social organizations is deepened, the function of "Bridge of Communication" is further amplified to provide services and resources to help civil society organizations achieve the "support" function of project tasks [3, 4]. In our country, the concept of "social organization incubator" was advocated in the early stage of the expression of supporting social organizations, namely, providing specific places and spaces to cultivate and support the initial social organization. Later, the "hub-typed social organizations" emerged, which place more emphasis on the role of "hub" between government and social organizations [5]. In general, the concept of "supporting social organizations" is much preferred by the academic community in recent years, given that it highlights its functional orientation more intuitively and tends to be clearer in the scope of its work. Specifically, a social organization does not directly serve the target groups, but provide through multiple channels the ordinary social organizations (also called service-oriented social 
organizations) with all-round support, such as training, funding, strategic guidance and etc.

The status quo of China's supporting social organizations is not the same as that of the West [6]. The western supporting social organizations' identity is similar to that of ordinary social organizations, with strong folk and grass roots nature, relatively pure positioning, and more focused support for social organizations. While under the historical and political influence, China's supporting social organizations not only provide support and guidance, but also play the role in transferring government functions and satisfying the demand of social governance [7]. It can be said that the complexity and diversity of China's supporting social organizations are unique. To analyze the Chinese mode of supporting social organizations, it is necessary to jump out of the single thinking of western social organizations, re-construct the theoretical perspective, and construct a new analytical framework.

Generally, the existing classification of supporting social organizations is mainly based on the following three frameworks. First is the classification of the organization's initiating background and operating entity, which is mainly based on the two dimensions of government and society [8]. Such as the mode of official background transition, the mode of government's vigorously support, the mode of spontaneous social forces, etc. Second is the classification of service attributes provided. Such as financial support, capacity support, information support, intelligence support, comprehensive support, etc. Third is the organization's service domain classification. Such as employees, teenagers, women and children, special groups and etc. [9] It can be seen that existing classification mode are all categorized from a single perspective, but the supporting social organizations in practice are all combined by multiple factors, so it is difficult to embody their complexity from a single dimension. Therefore, with a two-dimensional classification framework constructed in this paper, it principally attempts to explore deeply the characteristics of supporting social organizations from the theoretical perspective and puts forward the pertinent development suggestion.

\section{Classification Framework}

Relevant with China's special social environment, the initiator is a key variable for analyzing supporting social organizations.

For supporting social organizations initiated by government agencies, its working efficiency may be inferior to its high credibility. Unlike western social organizations launched by social folk forces, due to the deviation of the understanding of charity culture, China's once "big government" in the field of people's livelihood is accustomed to the package, and regards the social welfare related affairs as its own responsibility, which is a choice based on national conditions and political needs. Nowadays, although the environment has been improved, whether or not with the government background under the current situation of insufficient development to a large extent determines the credibility of supporting social organizations, the tendency of government resources, the discourse right of industries, etc. Therefore, with the endorsement of the government, the government-initiated supporting social organizations have higher credibility. However, due to the complexity of government administrative affairs, the social organization issues initiated by the government also tend to be confused with administrative affairs. The lack of accountability tends to lead to inefficiency, which is also the noticeable deal ends of government-initiated social organizations.

For non-government-initiated social organizations, its broad prospects and great potential overtake its uneven credibility. According to the theory of common governance of multiple entities, the main body of governance is multivariate rather than one-dimensional, with each entity being relatively independent and interconnected with each other, and collectively sharing the responsibility of public affairs governance within a certain range [10]. In essence, it is a mode of "multiple co-governance", in which, initiators such as governments, markets, and society are all involved. In China, however, the concept of government-led philanthropy has been deeply entrenched. Even for private philanthropy has lower and lower the barriers to entry, the "two-pronged" phenomenon of registration organizations and management departments on social organizations still changes inconspicuously. Even so, a demand for the development of social organizations is still spawned, and the enthusiasm and legitimacy of the market and society in social governance are also gradually rising. The innovation and activeness of non-governmental organizations have also injected fresh blood into the ecological community. With the increasing number of non-governmental organizations, it is unavoidable that there will be mixed results due to differences in capabilities. Relatively speaking, given the generally weak public credibility, the non-government-initiated social organizations still have a long way to go.

Sources of funding reflect the operational strategies of supporting social organizations, which are also variables that cannot be ignored.

The supporting social organizations with centralized funding sources are more efficient in raising capital, and their strategies of action are usually reflecting the willingness of investors. Based on the resource-based theory, the sustainable competitiveness of the organization can be understood by analyzing its heterogeneous resources. A form of "isolation mechanism", which includes information asymmetry, search matching costs for sponsors, etc. will be formed in organizations with concentrated sources of funding [11]. For example, concentrating sources of fund in the government will lead to a policy-oriented information advantage, while in the consortium, the flexible technological advantage of commercial means. The "isolation mechanism" makes it more difficult for organizations to be replaced, and also enables organizations of similar heterogeneity to gather together, forming the same type organization that distinguishes other organizations. This has led to a "separation" of organizations 
whose sources of funds are concentrated in different sectors, and the willingness of the organization will also act more often.

For supporting social organizations with diversified sources of resources, the characteristics reflecting on high financing costs, strong strategic independence, and more flexible and active operational modes. According to Resource Dependence Theory, all organizations must exchange with the environment in order to survive [12]. The need to obtain funds prompts organization's reliance on the external environment, and such reliance is usually accompanied with power. The funds from the government, market, and the public will all take their unique features, and correspondingly with relevant obligations to be fulfilled $[13,14]$. The more dispersed the source of funds is, the more circumvented the risk of becoming an "agent" of a certain department will be; and the higher the independent voice of the organization, the more flexible the operation mode will be; correspondingly, it turns out the greater cost of financing to invest in seeking different types of capital [15].

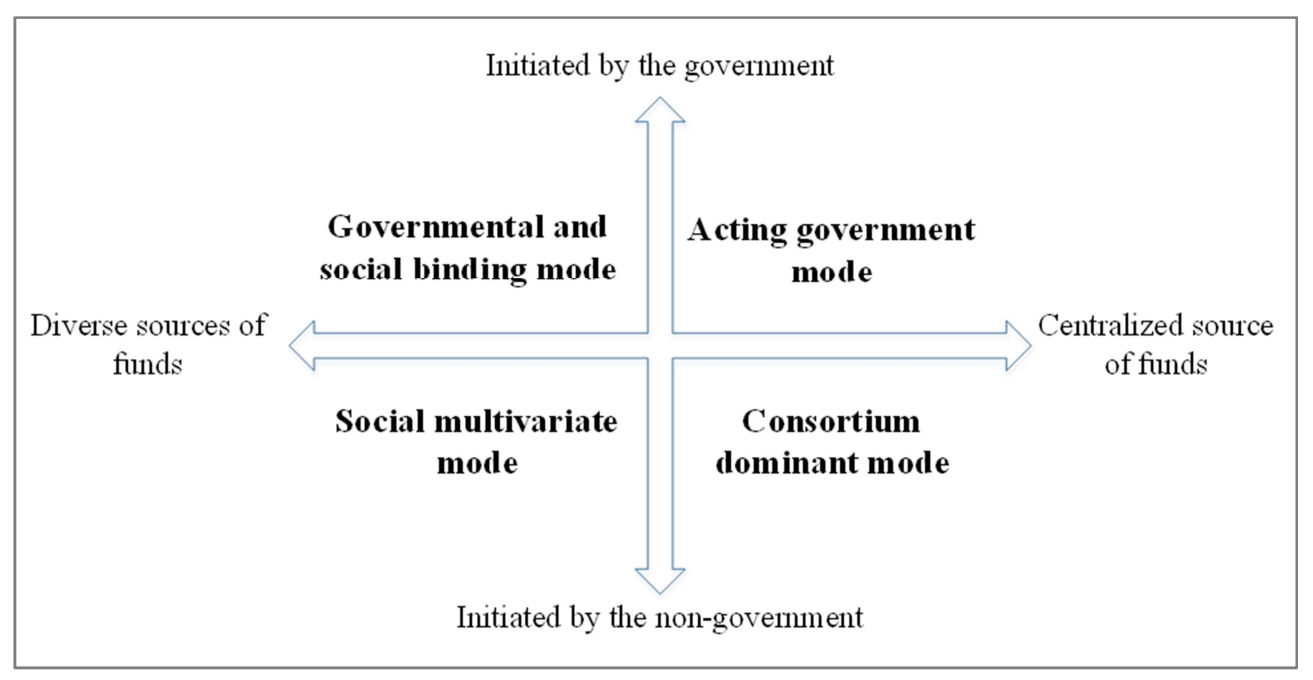

Figure 1. Supporting social organizations classification framework.

Based on the analysis above, the two dimensions basically determine the genes and future development direction of a supporting social organization. With the initiator as the vertical axis and the concentration level of funding sources as the horizontal axis, this paper divides all supporting social organizations into four modes from two-dimensional perspectives: Acting government mode (Initiated by the government--Centralized source of funds); Governmental and social binding mode (Initiated by the government--Diverse sources of funds); Social multivariate mode (Initiated by the non-government--Diverse sources of funds) and Consortium dominant mode (Initiated by the non-government--Centralized source of funds).

\section{Case Analysis}

In this paper, four types of supporting social organizations are discussed separately, with the representative cases selected for analysis.

\subsection{Acting Government Mode}

The supporting social organization under the mode of acting government is more like the agency of government function, which is often manifested as the hub-type social organizations in the previous discussion. Set up by the government, the person-in-charge of this kind of organization is usually the government leader or the head of the street community, who is responsible for social organization guidance, cultivation, supervision and other functions. Due to the uniqueness of its identity, it is easier to get all kinds of resources of the government. Therefore, they usually provide comprehensive cultivation services, such as office space, policy consulting, capacity building, project support, evaluation guidance and etc.

The social organization service centers at the county, street, and community levels all belong to this mode. Taking the $\mathrm{K}$-street social organizations service center in $\mathrm{J}$ district of $\mathrm{H}$ city as an example, since the registration in November 2011, there have been five core projects, and the public welfare venture projects are also organized in an orderly manner for social organizations in the jurisdiction. Among them, "Hand Dance Project", "Youth Self-help Project", "Class Stress Relief Project" and "Kale Project" (university of the third age) become the brand projects, with the number of beneficiaries over 200,000. Its core work is divided into three parts: First, promote social organizations that have been settled through financial support; second, allocate special funds to strengthen the capacity building of entered social organizations; third, organize community-level public welfare initiatives to screen more and better social organizations into service centers.

In terms of funding, according to the audit data of 2015 , $99.82 \%$ of the organization's revenue was derived from higher-level financial allocations, and the remaining $0.18 \%$ from interest income. Funding sources were highly concentrated in the government, which undertook the work related to local departments of civil affairs. It is noteworthy that the social organization service center's external 
propaganda is featured by party building. Under the Party building mode of "One Leader, Four Doubles, and Five Strongest", it has erected an example for many other communities nationwide. It also confirms from the other side that the organization, in addition to the cultivation and social organization work of community, also undertakes the government functions transfer and represents the government for a certain management work with more energy.

As can be seen from the case analysis, the supporting social organization under the acting government mode features as follows: First, financial sustainability is relatively high, but financial stability is strongly correlated with government policies. Second, it is easier to obtain various government resources and, as a result, they usually provide comprehensive cultivation services. Though receiving a high satisfaction from social organizations, it is also criticized for its complicated processes and many limitations. Third, the organization has a high degree of completion of annual plans, usually linked to government performance appraisal. Fourth, the organization only participates in government-related social organization activities, which causes its mediocre growth.

This mode of supporting social organizations plays an important role in the transfer of government functions. At this stage, under the premise of insufficient development of social forces, it is indeed necessary for such organizations to gradually separate from the function of social organization cultivation under government supervision. As a product of the transitional stage of social organizations development, it is the responsibility of such supporting social organizations to attract grassroots forces into social services and provide a platform for initial development. Even if the organization's geographical restrictions, capacity limitations, and financial restrictions all block its way of developing into a leader among supporting social organizations, but there is no denying that it weights a lot in helping and supporting grassroots social organizations.

\subsection{Governmental and Social Binding Mode}

This type of supporting social organization is usually initiated by the government, and the early development depends on the government's resource, which is usually the transformation of the official society. After transformation, the organization draws support from the market and social forces to develop, and gradually expands its sources of funding beyond government resources. It can even completely give up government subsidies, with funds all from social forces. However, it cannot be denied that their official background still has a strong voice in public trust when they raise funds, and that raising market funds for such supporting social organizations is just a piece of cake actually.

Taking the J District Social Organization Development Foundation in $\mathrm{C}$ city as an example, it can be seen from the name that the initiation of the organization is led by the local government, with the jointly funding initially from the government and the local company. Growing in size, it is the first local public foundation established at the district or county level to provide services for the development of social organizations. By the end of 2016, the total amount of current assets with source dispersed has been close to 35 million yuan, which is gradually moving away from the government to expand its own business.

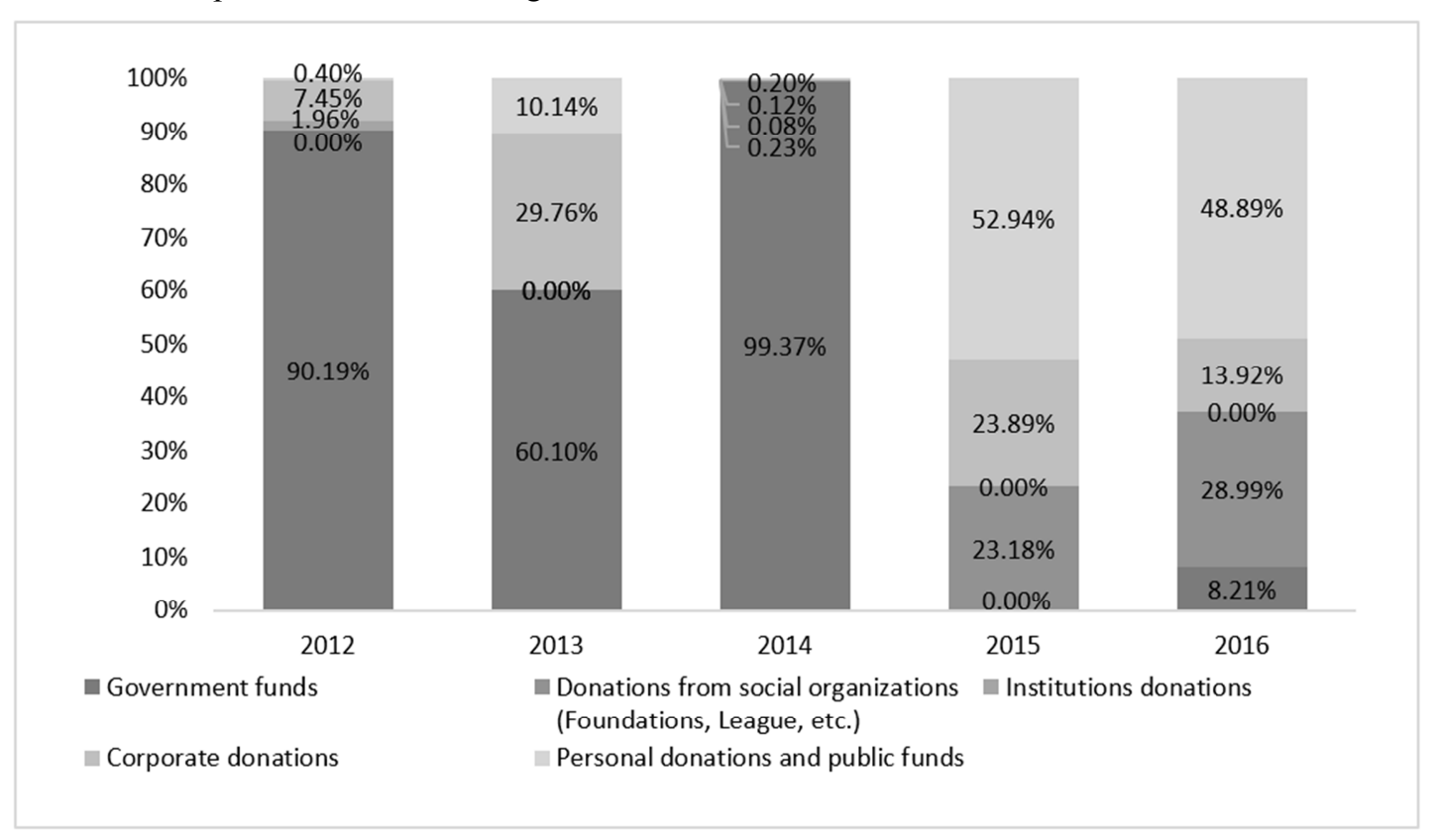

Figure 2. Changes in Sources of Funds for J District Social Organization Development Foundation in C city.

Since its establishment at the end of 2011, the change in the proportion of its various types of income is shown in Figure 2. In which, the source of funds is based on the "income" portion of the Business Activity table in the annual audit report. Considering that the source of "other income" is immeasurable, thus this part is excluded. Combined with the actual situation of this case, there was no income from contributions, service, sales of goods and investment, thus, 
only data of donations and government subsidy were selected. In order to specify the sources of funds, reference is made to the details of the donation income in the annual audit report ${ }^{1}$ As can be seen from the figure, the organization was still in the initial stage before 2014. The government granted large sums of subsidies in 2012 and 2014 respectively, which shows that for supporting social organizations, the government's initiative is conducive to establishing their advantages, cultivating their capabilities, and tapping future sources of funding so as to grow into a supporting social organization with market competitiveness as soon as possible. Since 2015, the increasingly diversified funding sources, the improved capital structure, as well as donations from all kinds of organization all have been involved, which also suggests that the organization's development is improving day by day, and it is no longer solely relying on government subsidies, and can still exert its own advantages to support other social organizations.

The development achievements of the foundation have also been recognized, which has broken the shackles of the transfer of government functions. For example, the sixth session of "Golden Thumb" college student innovation competition attracted more than 670 teams from over 120 colleges and universities, which promoted and funded the outstanding projects of each session. The "We Profit Project" has been oriented towards the social recruitment of more than 40 social organizations and has carried out all-round support for their cultivation. While the "TSP Seed Project" focuses on financial support and builds an interactive network that has funded 136 public welfare projects in five phases. In addition, there are many special projects, such as venture capital investment, research support, craftsmanship partner space, etc. which have gradually formed a network of public welfare support with their own organization as the core.

It proves from the example that the characteristics of supporting social organizations under the governmental and social binding mode are as follows: First, it develops with the aid of market and social forces and gradually expands its sources of funding besides government resources. Second, the local organizations take up the majority, with a high satisfaction with those social organizations they supported. Third, the organizations themselves are highly transparent, credible, effective and influential in the local area, in spite of their relatively weak power inside the industry. Fourth, a combination of the government and society endows those organizations with a promising future for their growth and development.

This mode is also essential for the development of supporting social organizations. Currently, for those domestic social organizations, on the one hand the absence of government support actually hinders their way of initial development. On the other hand, the excessive government

\footnotetext{
${ }^{1}$ This schedule usually only lists units or individuals that have donated more than $5 \%$ of the foundation's donated income or donated more than 5 million yuan in the current year. Therefore, the donation statistics of various organizations may be slightly biased, but it does not affect the overall situation of judging the donation ratio of various organizations.
}

intervention may degrade the social organizations to the functional agents of the government, lacking of autonomy and innovative vitality. This model is a better solution to this problem and is even a template for the transformation of the supporting social organizations under the acting government mode. This mode can not only further dilute the government's bureaucratic airs, fully mobilize social and market resources, but also effectively leverage the government's credibility as the initiator and the policy advantages to play a positive role in raising future funds, organizing development, and cultivating brand projects.

\subsection{Social Multivariate Mode}

The social multivariate mode refers to supporting social organizations initiated by non-government with diverse funding sources. Because of its lower credibility compared to government-initiated social organizations, raising funds for these organizations usually means more time and energy, as well as high technology. Regardless of the diversified sources of funds and difficulties in fund raising, such organizations are also likely to set up much influential and excellent examples with a high degree of philanthropy awareness.

The Heart to Heart Community Care Service Center in Y Province is an excellent representative of the supporting social organizations under social multivariate modes. Of which the founder is the director of Institute of Social Work in Y Province University, who has been studying on social work since the 1990s and has accumulated extensive experience in social work for her balance in research and practice. Besides, with the recognition that the cultivation of social work talents and organizations is very important, the institutions, founded under the mission of providing more professional technical training and capacity support, also touch the pain and shortages of small and micro social organizations. A major feature of the Heart to Heart was the establishment of Research Training Supervision Department in 2012, focusing efforts of scholars from universities and colleges in Y province to carry out training and supervision work. Relying on its own advantages of social worker talents, it has cultivated 25 social work service agencies and has grown into the only 5A-level supporting social organization in the region, which in turn, confirms that professional skills are conducive to the rapid growth of a grassroots supporting social organization.

Figure 3, based on public donation data after the Heart to Heart was transformed into a supporting social organization, shows the changes in funding sources in the past six years. It shows that, unlike government-initiated organizations, the funds for the organization's early development mainly come from donations from foundations and social organizations, accounting for a relatively high proportion. Since 2013, after accumulating a certain degree of popularity, the organization has also begun to receive government funds, in the form of purchasing services or undertaking projects, rather than directly accepting government subsidies. In addition, the organization's funding sources have also begun to decentralize, with the number of donations increasing from 58 in 2013 to 412 in 2017 . Although in the past six years, 
there is no remarkable change in the proportion of personal donations in the current year, the increasing number of donors and the fixed population of donation groups both indicate that the organization has developed towards a qualified supporting social organization with maturity and stability.

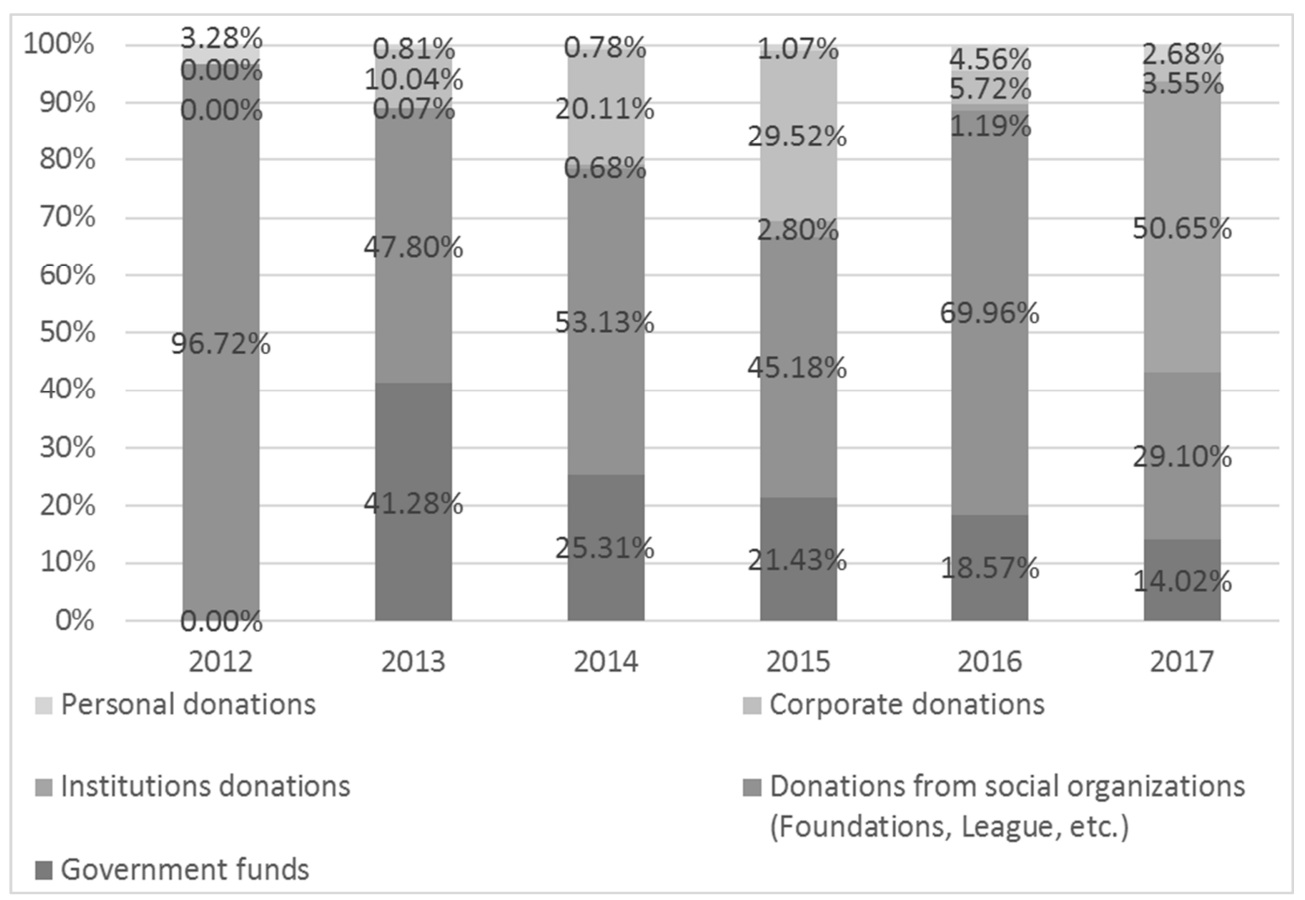

Figure 3. Changes in Sources of Funds for Heart to Heart Community Care Service Centers in Y Province.

In terms of the output, the Heart to Heart has set up a social organization promotion department to accelerate the development of social organizations. As of the end of 2017, 25 social organizations have been cultivated as social service agencies, which fully integrate the organization's expertise in social work. At the same time, given Y province's location in frontier ethnic minority areas and its complex geographical environment, the Heart to Heart, has introduced "Public Welfare County" Plan in line with the development features of the local public ecological environment, which was signed to foster the development of public welfare organizations in the county. More than 20 institutions was selected into the first group, forming a social work service learning network in Y province.

Although the Heart to Heart is a successful case, the supporting social organizations under the social multivariate mode is still the most difficult to develop in current domestic environment. It is hard for the real grassroots to have enough money and capacity to support other social organizations directly. As a result, this type of supporting social organization has the fewest numbers and the smallest size. In addition, other features are as follows: First, low financial sustainability. The funding sources is unstable. Second, the very few successful non-governmental multivariate organizations are usually uneasy to be copied. It is either dominated by influential leaders or has the professional support which is irreplaceable. Thus, support objects are highly relevant to organizational characteristics. Third, social influence is weaker than other types. The large gap in the level of organizational performance decides that it should be analyzed concretely. Fourth, such organizations have a high sense of charitable spirit with strong execution and concentration in areas they are good at. Therefore, they have great space for growth.

Despite facing so many restrictions, this mode is still an important new force to be concerned about. The organizations under social multivariate mode tend to be more sensitive about "down-to-earth". They can often find and solve tough obstacles, tricky problems, and urgent demands. In the course of discussions with many more competitive supporting social organizations, such organizations dig deeper into the real "pain points" of the present social organizations to give targeted support, arouse the enthusiasm of the grassroots social organizations, and make up their short board in a more practical way, so as to take their advantages and solve problems.

\subsection{Consortium Dominant Mode}

The largest group of supporting social organizations under the consortium dominant mode is non-public foundation, which are often the capital overflow of entrepreneurs themselves or consortium, so the foundation is set up to fulfill social responsibilities. With financial stability, they usually do not need to rely on external financial resources and seldom participate in government projects. Instead, they are highly targeted in their own projects, with high degree of freedom and outstanding innovation ability. Since such supporting social organizations are usually funded by one company or one individual, their donation field often reflect 
the willingness of donors, stable and specific.

Dunhe Foundation is a typical consortium-led supporting social organization that has risen in recent years. The original fund of 20 million yuan was donated by 13 individuals, including the chairman of Dunhe Asset Management Co., Taking the public data of 2016 as an example, the cash inflow of $0.2211,15$ billion yuan for all its business activities of the whole year was derived from donated income, which fully reflects the stability of the size and source of the supporting social organizations led by the consortium. With the mission of "promoting Chinese culture and human harmony", the company upholds the values of "respecting the Tao and valuing the virtue" and is in line with the corporate culture of DH Asset Management Co., Ltd. The funding field also focuses on the sinology inheritance, charity culture, public welfare and etc.

In the context of a highly centralized and stable funding source, Dunhe Foundation has the right to speak in its area of concern. Since its establishment on May 11th, 2012, it has participated in launching support for China Funder Round-table Forum, China Coalition for Public Welfare Fundraiser, and China Foundation Development Forum; initiated and co-founded important industry platform organizations, such as Shenzhen International Public Welfare Institute, Zhejiang University College of Rehabilitation, etc; planned and implemented a number of well-known brand projects, such as "Seeds Foundation", "Living Water Program", "Superior Talent Program", and "Bamboo Program", etc. In the first session of "Seeds Foundation", the top 20 social organizations have been selected from 363 applications to receive support for three consecutive years. Such achievements fully demonstrated the advantages of supporting social organizations led by the consortium, that is, tapping into the market potential and endowing social organizations with the power to participate in social governance and solve social problems.

Therefore, supporting social organizations under a consortium dominant mode usually have the following characteristics: First, the funds are large in volume and high in stability. Second, they are good at providing financial support and capacity building services, which satisfies the social organizations served by them. Third, this mode has the greatest social influence and is usually free of geographically restriction, which correspondingly lead to its high performance. Fourth, it seldom involves in government projects. Instead, with innovation ability and large growth potential, it has strong pertinence and high degree of freedom in its own field.

Most of the existing mature supporting social organizations in China belong to the consortium dominant mode. They have funds and sophisticated market operation modes, and they are best at using business acumen to judge support areas and select the appropriate social organizations. Although it is not ruled out that the use of market tools by individual organizations is overused, which are not particularly friendly to small and micro social organizations in the start-up period, there is even a suspicion of artifice of them. However, this mode still has its inherent superiority that other modes cannot possess, such as flexible settings, high degree of freedom, and strong fault-tolerance in fully tapping market funds into the social sphere, encouraging capital outflows and fulfilling social responsibilities, which, in return, will greatly benefit the development of the entire supporting social organizations.

\section{Conclusion}

The four modes of supporting social organizations have their own way of development, but the goal is to make more social organizations live and exert their power. As a transitional form of government function transfer, it is indispensable for the acting government mode to construct overall social organization network, so as to attract more social forces in solving social problems. Governmental and social binding mode is the transformation and upgrading of the former, and an excellent example of combing the current government and the market, making up the lack of universality and flexibility. Social multivariate mode has left the government's asylum, directly uses the folk force to discover the pain point, and then plays the specialized ability to obtain a place in the supporting social organizations, which is also the kind of support mode that naturally develops at the present stage. Consortium dominant mode allowed market forces to fully enter the field of social governance. While the commercial pattern brings supporting social organizations new vitality and challenges. The four modes function complementary with each other, which are the important components of the diversified ecological harmony and order of the supporting social organization.

Based on the separation of two classification dimensions in this paper, the government-initiated social organization has its own indelible official traces. No matter it is the source of funds, project introduction, or policy guidance, that always gives its inherent advantages. This kind of advantage is conducive to its rapid original accumulation, convenient access to government resources, as well as efficient building of credibility. The government-initiated supporting social organizations are more efficient than non-government-initiated ones and have stronger voice in the region. While non-government-initiated supporting social organizations have natural flexibility and freedom. With clear support goals and support intentions, their support areas are more in line with their own willingness and are easier to focus on a certain field. More specifically, it is more targeted to the social organizations that are supported and more inclined to address substantive issues in a certain area.

The supporting social organizations with concentrated sources of funds have obviously saved a lot of manpower and material resources in fund raising. The expected long-term financial stability is conducive to a more efficient and feasible long-term planning for a supporting social organization, which naturally helps social organizations become better. At the same time, long-term support is also given to play a greater role. However, when formulating 
project plans, it will surely be more or less limited by the sources of funds. The advantages of decentralized funding sources are mainly reflected the fact that they are relatively free to raise funds and can choose the source of funds that matches their values as much as possible. Though the financing process consumes more manpower and material resources, it is actually relatively necessary to assume responsibility for multiple donors. If the individual donors first recognize the organization's values and core projects, the entire project will be very successful in the implementation process.

The above analysis confirms that proposing a two-dimensional analysis framework is conducive to the government in identifying the attributes of supporting social organizations, and providing targeted transformation, support and advocacy. At the same time, supporting social organizations can also identify their own positioning, give full play to their advantages, and increase their competitiveness. In addition, a profound analysis of the development mode of supporting social organizations can encourage social organizations to actively participate in their own capacity building and seek support from various supporting social organizations based on actual needs. Furthermore, the public can also understand the inner working mechanism of supporting social organizations, so that each donation can find its destination.

Based on this, this paper proposes the following policy recommendations for the development of supporting social organizations:

Strengthen the professional capacity of the supporting social organizations under the acting government mode. Such organizations are relatively easy to develop under the requirements of "separation of government and society". Apart from solving a series of tasks such as cultivation, training, and evaluation, they also meet the basic requirements of separation work, such separation in activities, assets, sites, etc. [16] In addition, the natural advantages of such organizations are conducive to guiding the development of local social organizations. However, because of their limited capabilities, support for social organizations tends to be limited in growth. Hatching from scratch a social organization may be very easy, but it is more difficult for the start-up organizations to have their own core competence and still play a role without support. Therefore, it is necessary to improve its comprehensive capabilities for fostering social organizations and achieve optimal development.

Expand the effective scale of supporting social organizations under governmental and social binding mode. This kind of organization is the best way for the government to pry the market and social resources, and it is also the innovative way to strengthen the platform of social organization growth. Under the premise of guaranteeing effective operation, promoting the replication of this mode can solve social problems more effectively. Through the early stage of government subsidy investment and resources grafting, the political and social mixed mode organization has the ability to tap the market power on this basis, and change supporting social organizations supported by the government to supporting social organizations with self-hematopoietic capabilities. The multiple organic combination of the government, market, and society can allow them to focus more precisely on the pain points and give full play to their advantages.

Optimize the development environment for supporting social organizations under social multivariate mode. This kind of organization is often very difficult at the initial stage and it urgently needs the government to provide certain policy support. Encouraging competent or influential grassroots forces to participate in the supporting social organization field is also advocating a common vision and social consensus. The supporting social organizations of pure grassroots power are still scarce in China, with only a few relatively weak ones. It is necessary to build a favorable public ecological environment to cultivate more social pluralistic modes.

Advocate the orderly development of supporting social organizations under consortium dominant mode. Such organizations usually have relatively sound development plans and can also solve social problems by their own advantages. The government can encourage more entrepreneurs to put overflow capital into supporting social organizations, while advocating the self-discipline and more transparent and effective participation of the existing organizations in social governance so as to provide higher qualified social services, to allow more social organizations to share platforms and resources, as well as to jointly build a better development ecology.

\section{Acknowledgements}

This study was funded by National Natural Science Foundation of China (7167020488/ 71272166), Natural Science Foundation Outstanding Youth Project of Zhejiang Province (LR17G020001) and Philosophy and Social Science Planning Project of Zhejiang Province (No. 16NDJC169YB).

\section{References}

[1] Stremlau, C., 1987. "NGO Coordinating Bodies in Africa, Asia, and Latin America." World Development. 15 (3): 213-225.

[2] Padron,M., 1987. "Non-governmental development organizations: From development aid to development cooperation." World Development. 15 (1): 69-77.

[3] Brown, L. D., Arehana Kaxegaonkar, 2002. "Support organizations and the Evolution of the NGO Sector." Non-profit and Voluntary Sector Quarterly. 31 (2): 239-240.

[4] Brown, L. D., Tandon, R., 1994. Strengthening the grassroots: Nature and role of support organizations. New Delhi: The Society for Participatory Research in Asia.

[5] Beijing Municipal Commission for Social Work, 2009: "Interim Measures for Establishing Municipal "Pivot-type" Social Organizations Work System. 
[6] Saich, T., 2000. "Negotiating the state: the development of social organizations in China." China Quarterly, 161 (161), 124-141.

[7] Stoverink, A. C., Dan, S. C., Ning, L., \& Zheng, X., 2017. "Supporting team citizenship: the influence of team social resources on team-level affiliation-oriented and challenge-oriented behavior. Human Resource Management Journal, 28 (2).

[8] Snell, R., \& Hong, J., 2017. "Organizational Learning in Asia." Handbook of Organizational Learning and Knowledge Management.

[9] Skålén, P., Karlsson, J., Engen, M., \& Magnusson, P. R., 2018. "Understanding public service innovation as resource integration and creation of value propositions." Australian Journal of Public Administration (3).

[10] Eleanor Ostrom, et al., 2000: Institutional Incentives and Sustainable Development.
[11] Rumelt, R. P., Schendel, D., Teece, D. J., 1991. "Strategic Management and Economic." Strategic Management Journal. 12: 5-29.

[12] Pfeffer, Salanick, 1978. The External Control Organizations. New York: Harper and Row.

[13] Jun Han, 2016. "Policy Influence of Social Organizations in China." Nonprofit and Voluntary Sector Quarterly. 46 (2): 2-19.

[14] Andrea Chan, Sherida Ryan, Jack Quarter, 2016. "Supported Social Enterprise: A Modified Social Welfare Organization." Nonprofit and Voluntary Sector Quarterly. 46 (2): 261-279.

[15] Puljek-Shank, R., 2018. "Civic agency in governance: the role of legitimacy with citizens vs. donors." Voluntas International Journal of Voluntary \& Nonprofit Organizations, 1-14.

[16] Zhou, H., 2015. "Corporate philanthropy in contemporary china: a case of rural compulsory education promotion." Voluntas International Journal of Voluntary \& Nonprofit Organizations, 26 (4), 1143-1163. 